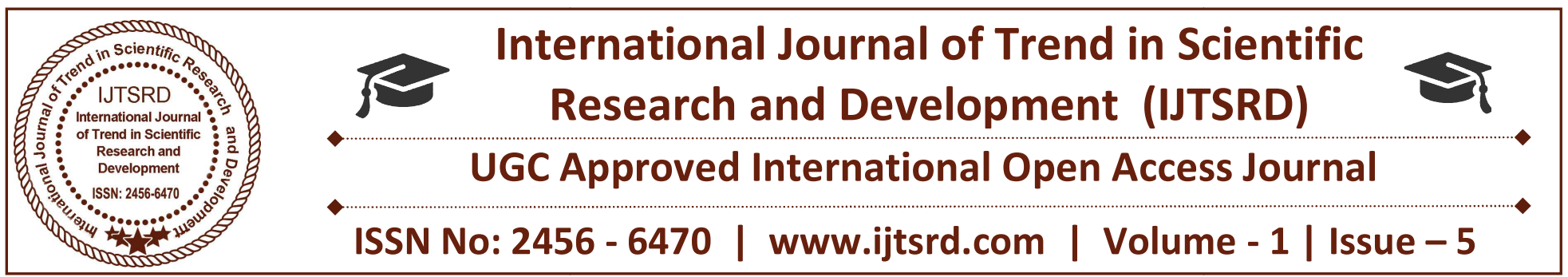

\title{
Legalization of Corporate Social Responsibility in Dealing with Environmental Issues "Examples from Moroccan Arab Countries"
}

\author{
Raed Awashreh \\ Independent researcher, Palestine
}

\section{ABSTRACT}

This paper focuses on the responsibility of companies in dealing with environmental problems that faces countries by asking the following question: What is the role that big companies should play in dealing with environmental problem? The hypothesis focuses on the need to have a legitimate role according to the law, which clarifies the responsibilities of companies towards environment sustainability and the interaction with the society, under the responsibility and leadership of the governments. The research paper is based on the inductive approach, accompanied by critical observations according to available data in secondary sources. The research examines the environmental problems faced by some Moroccan countries and how governments and companies deal with it. It highlights the gap in various types of treatment (preventive, therapeutic and developmental). Big companies are the primary beneficiaries from the geo-spatial and demographic space; however, their role in protecting environment is very limited. There is a need for laws and regulation to organize company role in protecting environment and ensure its sustainability. Laws to protect the interests of disadvantaged and marginalized groups such as rural areas and countryside. Mandatory laws vary from restructuring taxes and fees imposed on foreign and national companies, and imply policies and procedures to protect environment.

Keywords- Environment, Corporate Social Responsibility, Law, Moroccan Countries, Government.

\section{INTRODUCTION}

Problems that threaten both human life and environment are increasing. Some of these threats are related to the use of environmental resources in a manner conducive to their depletion. Examples: production processes, primary resource extraction of oil and other, different gases that lead to environmental damage, depletion of water supply and falling towards the scarcity of safe drinking water and nutrition. In addition to increase the demand over various types of resources, climatic and environmental changes affecting the ocean to nature and the universe. Previous examples are increasing the chances of putting human lives at serious risk and loss due to disease and environmental interactions create change conditions of continued life[1]. About third $(1 / 3)$ of planet's expected to suffer from scarcity of drinking water[2]. Water is an essential element for survival and sustainability of all living things, including humans. As it is expected to increase human suffering on Earth due to changes related to the environment; climate and natural resources needed to sustain life on Earth. One of the main causes of environmental problems is related to human relations actions; practices that threatening the survival of mankind through individuals and collective actions of organizations such as private companies and others [3].

Problem of environment is not aloof from political economy by virtue of its direct relation with the geographical space and population. Literature indicates thoughtlessness from western governments and companies in what's going in other States. Companies is ignorance and harmful when dealing with underdeveloped and developing countries; they 
try to take advantage of legal- political - social gaps to make profit and glorify it. Also, take advantage of weak governance for the purpose of obtaining licenses and perform actions affecting the environment and sustainability [4].

Attention to the environmental issue is increasing as a result of being a major incubator of life; to air, water, and shelter, no life can be outside the ecosystem. Maintaining and developing the environment are essential for serving current and future generation. This role should be of interest to political authority/ governments, major corporations, NGO's and private institutions. However, companies are interested primarily in profitability away from protecting environment and social concerns [5]. In 2005, The World Economic Forum in Davos has classified environmental situation in North Africa and the Middle East is low and weak [6].

The study pays attention to corporate social responsibility under direction and supervision of political authorities; tries to determine the gap between expected and current roles of private companies. The coming sections determine the used methodology and providing literature review and background information on environment and Moroccan countries situation and government plans. Next section presents findings based on gathered secondary data and critical marks. Last section is a conclusion with recommendation to enhance companies' roles in dealing with environmental sustainability and protecting human-being with empathies on marginalized groups.

\section{Research Question and Methodology}

What does it need to let companies playcore-active role in preservation of the environment and its sustainability? Further sub-questions: what is the current role of private companies- including major corporations, what does it need from government to maintain environment and its sustainability? The hypothesis goes for the need for clear legislations to identify the role of private companies in all phases and business operations related to environment. Therefore, the responsibility of governments is to formulate the needed legislations and ensure the implementation via leading and monitoring. This study relies on inductive methodology using facts existing in secondary resources- both researches and studies supported by critiques comments aiming to deepen knowledge and understanding over the issue.
In addition, a theoretical framework has used for processing data based on the fundamental role of political authority to govern and lead society issues and its different spaces (environment, population, geography, etc.). This framework also includes legalizing role of companies towards preserving the environment and environment affects on society.

\section{Literature Review and Background Information}

\subsection{Environment- a Pot for Living}

Environment is the frame of presenting and allowing living beings to exist; human, animals, and plants. Material in its solid - liquid - gas forms, conditions and forces such as light- sun- and wind, physics, chemical, and biological interactions need environment biosphere [7]. Climate change can be defined as a set of changes that occur in the Earth's climate over a period of time; an important example of these changes is high temperature, which were placed into high emissions generated from the Earth by virtue of human use industries. In such manner that planet of the land can be exposed to imprisoning of thermal dense and fast may change circumstances of the living on the land. The climate indicates the atmosphere and medium situations of the successive atmosphere in place what long-term genealogical. While the weather focuses are on changeable conditions from heat and winds, pressing and humidity in short genealogical period, night, a day or a week [8]. Climatic change contributes in the wars and causes military conflict sounds correct statement. A previous study stated that about $10 \%$ of wars and military conflicts broke out or/and intensified because of the climatic changes[9]. This example of war due to climate change is applicable on Arab countries where a number of the environmental problems caused numerous of clashes, wars, tension and aggressions from few countries. The Arab Organization for Administrative Development indicates that laws in Arabic countries do not include and clarity rules in protecting environment during wars [10].

Apart from wars, there are also problems resulting from manufacturing, production and various practices of man. Moroccan countries in particular and Arab countries in general faces challenges and problems that negatively affect the environment, including:

The steady increase in population, which is concentrated in urban areas and around the delta 
and the coastal strip of North Africa and the Arabian Gulf

Lack of freshwater quantity and deterioration of quality

$>$ Degradation of agricultural education, drought, desertification and coastal erosion

Waste and waste generation with no solid waste management systems

Poor institutional structures, legislative frameworks and legal structures that protect the environment

Focus on economic reform and structural adjustment and openness without serious preparation of these countries, which means negatively impact on the environment[11]

Changes in water rates and quality are important and vital sub-theme for the environmental profile. Decline and lack of water leads to killing of agricultural crops and lack of grass and water too, therefore affected all living organisms of humans, plants and animals i.e. all types of life. The decline and lack of water burdens the community, especially marginalized groups, poor families, and those who live in the countryside of farmers. This situation requires interventions from the government; include determining the role of the private sector specifically big corporation. The government's role and interventions should not be limited to provide food, water and temporary housing through tents for those affected by the environment. In the coming years, it's expected that water become a major problem as nearly one-third of the world's population will suffer from water, specifically drinking water. About 33\% of the world's population will be threatened by water scarcity; due to population growth, climate change, and activities harmful to water sustainability [12].

All type of Institutions should participate in therapeutic and preventive roles, but most importantly is the preventive and developmental roles. Roles that should formulated to plans based on studies and ongoing research. It's important to consider preventive and developmental options in the following areas:

\section{Afforestation and conservation policy}

$>$ Water conservation and use

$>$ Determine countries that can work together on interventions in environmental issues, neighbourly countries, countries with commercial and economic interests and relations, regional countries share a single biological destiny...etc

Alternatives to agricultural productions

Ways to preserve useful plant and animal wealth

Programs to compensate the marginalized poor because of damage caused by the effects and volatility

Studies of agricultural and livestock production options

Collecting rain by using several intervention tools without damaging the current and future environmental and human population components [13]

\subsection{Moroccan Plan}

The Kingdom of Morocco has prepared plans to address environmental challenges, including environmental and water fluctuations and the depletion of primary resources in economic activities. For example, in the area of water, there is depletion and decline; poor and marginalized communities face lack of water due to poor water supply system and discrimination in distribution as potable water concentrated in urban cities. Morocco also faces pollution problem of environment resulting from oil and its derivatives. To solve these problems Morocco has adopted an implementation plan for addressing the environment file. Protecting environment from challenges such as climate change, other effects, coastal areas and port. In addition to government efforts, a number of associations have been established to protect fishing and natural resources. Also, a number of memorandums of understanding have been signed and some facilities have been provided for institutions that work in protecting the environment for institutions and individuals, such as tax exemptions, which are studied in individual cases. Although in 2002, Morocco ranked 49.1, the country's 73 th in terms of environmental sustainability but still it faces from weak institutional performance[14].

There are two plans dealing and addressing the environment issue: the National Plan and the 
Environmental Protection Operational Plan [15]. These plans aim to develop and strengthen the environmental concern related to economic activities focusing on the following topics: water, waste, air, rural areas and adjacent to the sea administrative and pollution. The plans have set three long-term objectives: developing a legal and institutional framework, an integrated policy based on cost-benefit analysis, building on the quality of the environment and the necessary investments, plus development policy summaries as described in order to avoid the resulting environmental problems in the medium term And long-term environmental protection[16].

As for institutional work, there are a number of government institutions that deal with the environment; their role and effectiveness is low due to high centralization associated with the slow and nonparticipation and disclosure of information. However, government is willing to change and make changes; some indicators show this willingness: reducing centralization and giving provincial authorities responsibilities in handling and dealing with the preservation of the environment. Another constraints are the low number of non-governmental organizations involved in the sustainability, conservation of the environment, and the difficulty of licensing such institutions [17].

\section{Findings \& Discussion}

\subsection{Role of Governments and Organizations}

It is the responsibility of governments first to develop necessary legislations and policies for the preservation and sustainability of the environment, in addition to supervise and implement of legislation and policies. Private companies are primarily seeking profits; they do not take the environmental issue seriously unless it is through governmental legislation and supervision or by providing profitable projects for the purpose of preserving and sustaining the environment. The Algerian government has developed the National Climate Plan 2015-2050 to reduce and reduce carbon emissions, produce and increase clean energy production, develop a climate structure adapted to climate change, adopt appropriate agricultural policies and strategies and climate change. It also worked for the importance of the subject to adopt a plan to produce clean energy instead of burning oil and various derivatives through the plan (2011-2030) [18].

The UN report indicates that 16 large companies have obtained certificates of completion of social responsibility standards from the Institute of Algerian Standards and Metrology, including dealing with environmental issues. The direct role of companies comes in the context of the call for green economy, reduction of gases, emissions from industrial processes and productivity, preservation of the environment. Therefore these companies must be interested in research, studies and innovations for the purpose of preserving the environment [19]. It is important that government has a role in monitoring to protect environment from threats and damage that might affects its sustainability. Also, to impose value on these companies by allocate funds and support research - universities in Moroccan countries.

An example, how can the governments help 25,000 families whom have affected by environmental fluctuations in few of Algeria's states? Algerian intervention was limited to emergency - relief aids; provide blankets and food to keep bodies warm and people survival. These are urgent therapeutic interventions, however, developmental interventions are needed to sustain the sustainability of human activity and environmental resilience as well [20].

Politics has major influence on the environment; foreign policy of countries must be confined to the environmental space of other countries away from strengthen their international political and economic weight. Any changes that have repercussions on and within the superpowers or Western governments intervene directly and strongly, while they do not worry about any environmental changes that have no impact on their countries. Governments across the World focuses only on local - national interests; states selfishness is increasing over five continents. National slogan has caused to limit environment awareness in what is happening within the scope of national countries only. Thus, there is logic behind the claim that economic openness contributes to environmental problems; noting problems will not have direct and equal impact on all countries [21]. Commercial and economic openness increases environmental problems and harms over recipient countries. Recipient countries can be described as economically pivotal countries, dependent states, and developing countries.

\subsection{Gap in Companies' Role}

There is a clear gap between the needed role and actions of private companies towards environment sustainability. Current role of corporate social 
responsibility is a set of promotional activities aimed at increasing the value of companies' assets, gaining benefit- facilitation from communities and governments. The consideration of social responsibility on the ground is still within the marketing plans and does not go or reach the framework of dealing seriously with the environment sustainability. The trend must be in legislating the role of corporations in dealing with environment and its impacts, especially towards the poor, marginalized and rural communities. Social responsibility requires codification rather than leaving it optional. Leaving it optional makes this responsibility under the weight of barter by large companies in their dealings with governments for the purpose of access to further benefits and facilities. However, the role that is required by companies should be allocating amounts from their revenue and income for the benefit of geographical sites and marginalized groups. On the other hand, one of the key roles companies must play is adopting friendly manufacturing system and friendly products. Example on friendly views; wastes that are analyzed and reused, production processes that minimize the risk of any negative impacts on the environment, prepare and carry out preventive actions for the benefits of environmental sustainability [22].

\subsection{Escaping from Legislation}

Companies may try to reject the idea of legalizing the role of companies in protecting the environment for various reasons and pretexts in order to evade responsibility and escape from any financial obligations.

Companies can argue that their contribution to the economic process and diverse business sectors are real contributions to the preservation of environmental sustainability.

Companies are committed to the laws and legislations enacted by the government in the preservation of the environment; do what they can to preserve the environment and not endanger the sustainability of the environment through research and development and social responsibility, in addition to their commitment to the rules of work and government legislation.

Social responsibility should be optional to companies because of many reasons: environment is not limited to companies as it the government responsibility at first stage as well as further institutions and community. The legislation may increase the financial burden on companies, and will hurt the aspirations and perspectives of investment and the movement of attracting investment. Companies can collect these fees and taxes from people and thus increase additional burdens on the community [23].

\subsection{Environment and Citizens' Rights}

Some countries impose restrictions laws on individuals - environment relationship; these laws affect both individuals and communities. Environment sustainability must not be isolated from living and communities sustainability. Communities and individuals, especially the poor, have rights to benefit from environment and its sources. Individuals have the right to enjoy nature resources of water, plants, food and animals within the limits of no harm to the environment. This means that they have a duty to preserve the sustainability of the environment. However this equation is not only for the two parties: community and the environment, it should includes other major parties, government and companies to ensure sustainability of people and the environment [24].

For example, waste disposal requires that government stake necessary intervention to protect society and the environment. Communities and individuals cannot be called upon to maintain their fortunes without doing the required tasks needed by the government in preserving and sustaining society. Farmers who have livestock need to interact with the environment for the purpose of feeding these cattle and re/production of milk and dairy products. If governments prevent grass feeding, this needs logical solution that does not harm the peasants and their communities. Another example, it's hard to ask farmers to move from their locations or force them to buy other property they cannot afford or live in[25]. On the other hand, when environment is harmed by weather fluctuations, for example, the state must intervene in favor of preserving the community and protecting resources. Government interventions should include initiatives to ensure sustainability of life and in favor of marginalized groups interest.

In order to ensure compliance with laws by individuals, it is necessary not only to issue laws but also to deal with the effects of these laws when it 
comes in protecting environment[26]. In order to prevent hunting and extinction of animals legally, it is necessary to sensitize public and provide alternatives for them to continue their survival. A large number of people survival in coastal areas depend on fishing from water and conservation of fish and aquatic resources. Users may be required to stay away from fishing for periods of time and geographical locations that may affect their lives especially fishermen live on a daily bases. Also, bad weather conditions can affect fishermen. This requires government intervention to preserve the rights and sustainability of human life as well as to ensure the sustainability of the environment [27].

Those affected by environmental fluctuations have rights related to their humanity and citizenship and need government intervention. It's impossible to ask poor people, marginalized group and the peasants to buy bottle drinking water. Such responsibilities within government hands and also requires private sector contributions. These contributions should not be left to choice, or to the exchange of benefits for additional facilities aiming to increase corporate profits. The questions should be asked, what interventions are required by the government, laws and legislation needed to ensure sustainability of both human life environment? And how to determine roles and obligations for parties in these interventions.

\subsection{Sustainability Indicators and Role of Companies}

The United Nations bodies have developed indicators to measure the sustainability of the environment; they have been defined as indicators for sustainability that based on five sub-indicators:

Ecosystem Index based on indicators of air quality, biodiversity (biology), land quality and quantity of fresh water.

A measure of the low pressures on the environment such as reducing air pollutants and reducing pressure on the ecosystems and the sound management of waste in all its forms.

Reducing human exposure to environmental pollution and waste of natural resources, such as environmental health, livelihood and livelihoods, while minimizing risk from post-disaster situations.
$>$ Guide to measuring community and institutional capacities such as environmental governance, efficiency and responsiveness of the private sector.

$>$ Responsibility for global environment, including engagement in international efforts to protect the environment, reduce greenhouse gas emissions and reduce pressures on the trans-boundary environment [28].

The Environment Sustainability Report indicates that there is partially response by the private sector in Tunisia and Morocco in protecting the environment and taking necessary measures. Opportunities to expand the role and response of the private sector to sustainability are required serious steps [29]. International reports summarize the dire situation of Moroccan countries in sustaining environmental; it is limited effort and partial intervention. Advocacy development and governance improvement over societies and government $\mathrm{n}$ their relations to the environment shall contribute to improving environmental sustainability [30].

\section{Results}

The findings present the gap between the required and played role by companies; where role of protecting environment is limited and therefore a need to increase and activate it. The first step is to legislate companies' role. Second, formulate policies and plans and implement them in which involve companies in these plans. In addition, the government in plans should control and monitor companies involvement to ensure that they play their role in away to preserve the environment and sustainability and take social responsibility towards the communities.

It is also necessary to develop a system of legislation and strategies that take into consideration the nature, quality and requirements of environmental sustainability in relation to community-individuals and their social and economic life. Environment sustainability benefits of human life, thus, strategiesprograms- plans- interventions- and definition of quality needs the participation of all society' components. It is also important to clarify and identify government interventions based on the development of national and regional strategy. In additions, it needs to draw a key intervention that can be done by government including legislation and role of companies in preserving environment sustainability. 
These interventions include:

Preventive interventions: interventions on different aspects and sectors of business to avoid harm to the environment through the formulation of laws, legislation and policies and the development of plans and programs that relate to institutions and individuals and the community. The most important is preventive interventions awareness, education and control of all activities for business.

Treatment interventions: these interventions are intended to treat and repair environmental damage, which also contains mandatory practices for the private sector, and correction practices resulting from regulatory processes.

$>$ Development interventions: developing strategies, policies and programs and set objective to contribute in developing the environment in its relations to individuals and communities. Scientific research, invention and creativity occupy a major focus for the purpose of contributing to the improvement of the quality of the environment and human life. Joint ventures between private and public sectors can be part of the environmental sustainability interventions. Joint projects aim to generate clean energy and reduce oil burning, desalination, and legalization of water use [31]. However, joint ventures should not become a bridge to a private sector to generate revenue instead of severing community first and make profit in second place to companies. Also, it important to be aware of any corrupted opportunities might corporate rise to manipulate government officials.

These interventions can include all aspects; legislation of duties, taxes and social responsibility funds, not to leave things optional, spontaneous hostage to the economic interests of private companies, particularly big corporations. In addition, interventions and awareness programs are needed to help sustaining environment, and conduct various scientifictechnological-research intervention [32].

Charges / Taxes: Study the possibility of charging fees and taxes for the benefit of environmental sustainability with relations to local community. However, these fees and charges should not be taken from people pockets. For example, fees to protect and develop environment, mandatory contributions according to company sizes- revenues - profits. It is also necessary to allocate funds for research centers for the purpose of innovation and carrying out a distinguished scientific, in addition to the effects of fluctuations and various environmental changes on human life [33].

Provide the means and tools that ensure prevention, preservation and development of the environment for local communities and populations, especially marginalized groups. The concern for rural areas and marginalized groups should be at the center of the concerns of government interventions. The countryside accounts for $60 \%$ of the total area and population of the Moroccan countries and has a small income that relies heavily on the environment [34]. There is a need to pay attention to the countryside, including the development of community and individual awareness towards the environment and nature resources.

Also, interventions in favor of the countryside must be based on understanding of how government laws and legislation can be harmful or limit the exercise of people rights especially marginalized and rural communities. In addition, companies should engage in protecting environment as they using natural resources, and responsible in draining environment to make profits.

\section{Conclusion and Recommendations}

Governments are the responsible authorities in governing and managing the country's affairs, including environment related issues. Government roles are in formulating national and regional strategies, setting strategies and policies, putting positive intervention in favor of environmental sustainability in its relationship with local communities. Among the most important interventions is legalization the role of big corporation and private sector in relationship and dealing with environment. Legalization should impose over preventive, remedial and developmental legislation and determining the responsibilities and duties of the big companies, their financial contribution in environment sustainability plans and initiatives. This contribution should come from company's revenues not taken from consumers and citizens'. Also, should be an interest in study intervention in protecting environment to its relationship with marginalized areas such as rural areas and coastal areas for the categories of fishermen and farmers. Same to study 
alternatives for the purpose of protecting people rights and sustaining their lives when formulating treatment - prevention and development environmental policies.

A very important recommendation is the need for research centers that integrate environmental and socio-political studies, and to review current laws and technical interventions according to policies and programs rather than reactions and relief assistance. The need of caring for and sustaining the environment includes relief, prevention, development, sustainability and attention to the rural, poor and marginalized groups.

\section{$\underline{\text { Reference }}$}

[1] Wikipedia, last Access 10 May 2017 fromhttps://ar.wikipedia.org/wiki/

[2] United Nations Environment Program. Background paper for ministerial-level participation on water, sanitation and human settlements. Environmental Report (UNEP Report 2004, p. 4).

[3] Christain -Albrechts University, last access 10 May 2017 from

http://www.unikiel.de/ecology/users/fmueller/salzau2 006/studentpages/Human_Environmental_Interactions /index.html; Wikipedia Website, Human impact on the environment, last access 11 May 2017 from https://en.wikipedia.org/wiki/Main_Page; The impact of climate change on humans. Last access 2 April 2017 from

\section{https://ar.wikipedia.org/wiki/}

[4] Nath, V. (2001). White Collar Invasion: developed country policies leading to environmental degradation in South. London School of Economics. Last access12 May 2017 from www.cddc.vt.edu/knownet/whitecollar-paper.doc;

Najib Musab. The environment between local and global. Green Line. Last access 3 April 2017 from Http://www.greenline.com.kw/ArticleDetails.aspx?tp $=312$

[5]Patrick et al. (2006). Report prepared to European Commission under Contract No: Europe Aid/114340/C/SV/CME: Impact Assessment Research Centre. Institute for Development Policy and Management University of Manchester; United Nations Economic Commission for Africa Office for North Africa. (UNEC). 2014, The Green Economy in
Algeria. an Opportunity to Diversify and Stimulate Domestic Production;

[6] Arab Organization for Administrative Development (2010) The role of legislation and laws in the protection of the Arab environment. Research Papers. Cairo, Egypt.

[7]The McKEEVER Institute. 2004. Morocco Economic analysis of government's policies, investment climate and political risk; Northern Africa: Algeria and Morocco and Tunisia. Last access February 16, 2017 from the World Web:http://www.worldwildlife.org/ecoregions/pa0513

[8] Climate Change: Can we save our planet from

climate change? Last access 29 March 2017.

Https://infosantejeunes.usj.edu.lb/files/dossier.htm?id $=92 \& \lg =2 \& \mathrm{p}=1$

Climate change on Earth. Last access 30 March 2017 from Https://www.ts3a.com/bi2a/ ;

Climate variability. Why has it increased in recent times?

Last access 30 March 2017 from

Https://www.ts3a.com/bi2a/ Volatility-

[9] Ramallah News Website, last access 15 March 2017 from: http://ramallah.news.

[10] Arab Organization for Administrative Development.(2010). The role of legislation and laws in the protection of the Arab environment. Research Papers. Cairo, Egypt.

[11]Arab Organization for Administrative Development (2010) The role of legislation and laws in the protection of the Arab environment. Research Papers. Cairo, Egypt.

[12]United Nations Environment Program. Background paper for ministerial-level participation on water, sanitation and human settlements. Environmental Report (UNEP Report 2004, p. 4).

[13] Tarradell. M (2004). Morocco Case Study Analysis of National Strategies for Sustainable Development. ) Environmental Policy Research Centre Freie Universität Berlin. Last access February 13, 2017. From the World Web: http://www.iisd.org/ measure/capacity/sdsip.asp

[14] Tarradell. M (2004). Morocco Case Study 
Analysis of National Strategies for Sustainable Development. ) Environmental Policy Research Centre Freie Universität Berlin. Last access February 13, 2017. From the World Web: http://www.iisd.org/ measure/capacity/sdsip.asp

[15] Tarradell. M (2004). Morocco Case Study Analysis of National Strategies for Sustainable Development. ) Environmental Policy Research Centre Freie Universität Berlin. Last access February 13, 2017. From the World Web: http://www.iisd.org/ measure/capacity/sdsip.asp

[16]Souissi. A (2001) . Report- Environment and sustainable development issues and policies. Mediterranean Country Profiles Tunisia. Sophia Antipolis; Mireia Tarradell. M (2004). Morocco Case StudyAnalysis of National Strategies for Sustainable Development. ) is Centre Freie Universität Berlin. Last access February 13, 2017. From the World Web: http://www.iisd.org/ measure/capacity/sdsip.asp

[17]Souissi. A (2001) . Report- Environment and sustainable development issues and policies. Mediterranean Country Profiles Tunisia. Sophia Antipolis;

Tarradell. M (2004). Morocco Case Study Analysis of National Strategies for Sustainable Development. Environmental Policy Research Centre Freie Universität Berlin. Last access February 13, 2017. From the World Web: http://www.iisd.org/ measure/capacity/sdsip.asp

[18] United Nations. The Algerian government has developed the National Climate Plan 2015-2050. Last access 30 April 2017 from

http://www.uneca.org/sites/default/files/uploadeddocuments/SROs/NA/AHEGM-ISDGE/egm_gealgeria.pdf

[19] United Nations. The Algerian government has developed the National Climate Plan 2015-2050. Last access 30 April 2017 from

http://www.uneca.org/sites/default/files/uploadeddocuments/SROs/NA/AHEGM-ISDGE/egm gealgeria.pdf

[20] Algerian newspaper, Al-Bilad 26/2017. Statistics of 25 thousand affected families across the country measures of climate variability. Last access $30 \mathrm{March}$ 2017 from
Https://www.elbilad.net/flash/detail?id=39571

[21] Hilmi, N. Safa, A. \&Ketata, I. (2015) Environmental risks, policy decisions in large multinational companies and policy makers in Tunisia. Middle Eastern and African Economies Vol. 17, No. 1.

[22] Salls, M. (2005). Corporate Responsibility and the Environment: What is the Right Thing To Do? HBS Working Knowledge - Harvard Business School Last access 20 February 2017 from the World Web: http://hbswk.hbs.edu/item/corporate-responsibilityand-the-environment-what-is-the-right-thing-to-do

[23] Government of the Netherland. Roles and responsibilities of provincial government, municipal governments and water authorities. Last access 10 may 2017 from

https://www.government.nl/topics/environment/conte nts/roles-and-responsibilities-of-provincial-

government-municipal-governments-and-waterauthorities.

[24] UNECA. The green economy in Algeria . last access 20 April 2017 from

http://www.uneca.org/sites/default/files/uploadeddocuments/SROs/NA/AHEGM-ISDGE/egm_gealgeria.pdf

[25]Alkuwaityeah news. «Fish stocks» foreshadow an immediate disaster. Last access 13 May 2017 from http://alkuwaityah.com/Article.aspx?id=420388Mireia

[26] Kamal Zerq. Role of Government in Protecting Enviorment. Last access 12 May 2017 from https://revues.univ-ouargla.dz/index.php/numero-052007/742-2013-05-07-14-48-30.html

[27]Albadil news. Akhnoush: hunting on average lives in a worrying situation. Last access 13 May 2017.

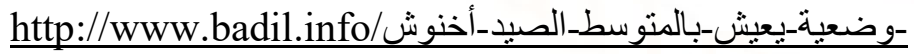
/مقلقة /

[28] Arab Organization for Administrative

Development (2010) The role of legislation and laws in the protection of the Arab environment. Research Papers. Cairo, Egypt.

[29]United Nations Environment Program. Background paper for ministerial-level participation 
on water, sanitation and human settlements. Environmental Report; GIZ. (2016). The portfolio of GIZ Algeria. Environmental governance and sustainable development.

[30] Arab Organization for Administrative Development (2010) The role of legislation and laws in the protection of the Arab environment. Research Papers. Cairo, Egypt.

[31] GIZ. (2016). The portfolio of GIZ Algeria. Environmental governance and sustainable development

[32] Arab Republic of Egypt: Ministry of State for Environmental Affairs. Sustainable Development in Egypt: Efforts and Needs. Last accessed 8 January 2017 from the website Https://sustainabledevelopment.un.org/content/.../320 1egypt_b.pdf
[33] Patrick et al. (2006). Report prepared to European Commission under Contract No: Europe Aid/114340/C/SV/CME: Impact Assessment Research Centre. Institute for Development Policy and Management University of Manchester;Mireia Tarradell. M (2004). Morocco Case StudyAnalysis of National Strategies for Sustainable Development. ) Environmental Policy Research Centre Freie Universität Berlin. Last access February 13, 2017. From the World Web: http://www.iisd.org/ measure/capacity/sdsip.asp

[34] United Nations Environment Program. Background paper for ministerial-level participation on water, sanitation and human settlements. Environmental Report (UNEP Report ); United Nations Environment Program.(2001). Mediterranean Country Profiles. Environment and sustainable development issues and policies 